\title{
Evaluation of the Need for and Design of a City Energy Operations System
}

\author{
Mary Ann Piette \\ Building Technology and Urban \\ Systems \\ Lawrence Berkeley National Lab \\ Berkeley, CA, USA \\ mapiette@lbl.gov
}

\author{
Reshma Singh \\ Building Technology and Urban \\ Systems \\ Lawrence Berkeley National Lab \\ Berkeley, CA, USA \\ reshmasingh@lbl.gov
}

\author{
Anand Krishnan Prakash \\ Building Technology and Urban \\ Systems \\ Lawrence Berkeley National Lab \\ Berkeley, CA, USA \\ akprakash@1bl.gov
}

\begin{abstract}
There is growing interest in city and community scale energy efficiency goals across the US and around the world [1]. Forward thinking developers are expressing interest in developing methods to track the actual operations of new urban developments and campuses. Local governments and developers are exploring how to ensure that the built infrastructure, including buildings, transportation, energy generation and storage assets, is not only designed for energy efficiency, but operates efficiently as well. There is a need for city and district scale tools to support energy analysis from design through operations. Smart city data analytics is a growing area of interest in the smart city technology space. However, while there is enthusiasm for the concept of smart city energy analytics, there is a lack of common semantic data models, interoperable systems, and methods to collect data and support decision-making for operating multi-building city- and districtscale energy systems. Urban developers are asking broad questions about how such a system might be designed, built, valued, maintained, and optimized. This paper describes ongoing research to explore and define a City or District Energy Operations System (CityEOS).
\end{abstract}

\section{CCS CONCEPTS}

- Information systems $\sim$ spatial-temporal systems • Information systems $\sim$ Data management systems $\bullet$ Human-centered computing $\sim$ Visualization application domains $\cdot$ Applied computing $\sim$ Environmental sciences

\section{KEYWORDS}

City Energy, Building energy efficiency, Mobility and energy, Energy generation and storage, City data exchange, distributed energy resources, district energy systems, decision science

Publication rights licensed to ACM. ACM acknowledges that this contribution was authored or co-authored by an employee, contractor or affiliate of the United States government. As such, the United States Government retains a nonexclusive, royalty-free right to publish or reproduce this article, or to allow others to do so, for Government purposes only.

UrbSys'19, November 13-14, 2019, New York, NY, USA

C 2019 Copyright is held by the owner/author(s). Publication rights licensed to ACM.

ACM 978-1-4503-7014-1/19/11 ..\$15.00

https://doi.org/10.1145/3363459.3363539

\section{ACM Reference format:}

Mary Ann Piette, Reshma Singh and Anand Krishnan Prakash. 2019. Evaluation of the Need for and Design of a City Energy Operations System. In Proceedings of UrbSys'19, New York, NY, USA, November 13-14. https://doi.org/10.1145/3363459.3363539

\section{INTRODUCTION}

This paper describes ongoing research to explore and define a City or District Energy Operations System (CityEOS). The concept of a CityEOS was developed based on results from interviews with key stakeholders and potential EOS developers. The interview explored the basic question - what is the potential value of an integrated energy information and real-time platform that can provide energy data across various sectors at the city or community scale?

Specific topics of interest in the interviews included (i) defining current and aspirational use cases for different stakeholders in a city's energy domain. (ii) challenges in data access (open vs. proprietary) and system interoperability (iii) data sources for the operating platform and avenues for data collection (iv) potential data analysis applications and technology adoption scenarios and how they relate to sustainability goals and (v) dashboard and user interface technologies for visualization of data to aid in various levels of decision making.

City energy managers, commercial real estate developers, campus energy managers, municipal energy utilities, technology vendors, environmental advocacy firms, and architectural and urban design firms were interviewed to learn about their challenges with energy management, how they have been dealing with it and how they would like to deal with it in the future.

As part of this project, there is also an effort aimed towards the development of a reference specification that can be used to scope and implement a CityEOS. Several cities have expressed interest in piloting the use of the specification to evaluate their ability to implement pieces of the vision in a CityEOS. 


\section{APPROACH}

To determine a framework for the reference specification, we followed a five-step discovery approach, as shown in Figure 1, that was influenced by the results of a literature review, technology review and the stakeholder interviews. We reviewed 14 technology platforms (both proprietary and open source) that exist today and are aimed at managing data coming from different sources at a city level. Some of them come with pre-built applications and analytics, while others are quite flexible that they allow users to build their own applications.

The process began with step 1 - identifying the key use cases that our stakeholders wanted the CityEOS platform to support. The stakeholder interviews and the review of the existing platforms and literature fed into this and we refined the set of use-cases that we wanted CityEOS to handle. In step 2 we identified the metrics needed to support these use cases. In step 3 we determined what type of data (e.g.: energy consumption data, emission data etc.) the metrics need to be expressed in, and from where and how do we acquire each of these data (e.g.: Green Button Meter data through a web API, environmental sensor data through device drivers etc.). In step 4, we abstracted these data into visualization, in order to provide useful information for the user, identifying what charts meet the use-cases laid out in step 1 and what data are needed. In the final step 5, we suggest to the users of the platform how to interpret the charts and identify possible actions that might be taken.

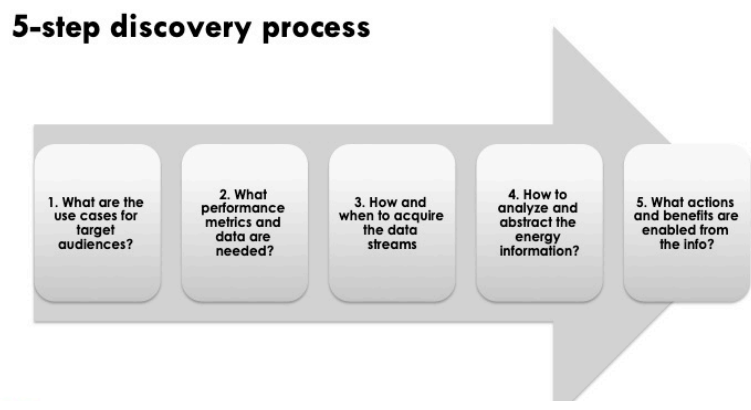

Figure 1: Five Step discovery process for CityEOS

Through the process we identified common use cases, metrics, data streams and visualizations of interest to the key city and campus stakeholders. This informed the scope of a city's energy data acquisition, storage and analysis platform.

\section{RESULTS}

\subsection{Use Cases}

For our 28 stakeholder interviews we categorized the use cases under three headings: Planning \& Policy (City/Campus), Design \& Build (Developer), and Operation \& Maintenance (Utilities).

The use cases in the Planning \& Policy "City/Campus" section focus primarily on energy inventorying and reporting, sustainable energy target setting and energy benchmarking. These are the critical points that city managers, planners, consultants, utilities, and distributed energy operators focus on through different energy interventions at city, campus, building, transport and utility levels. Longitudinal and cross- sectional benchmarking are important use cases that help asset owners and managers identify trends and achieve accountability.

The Design \& Build "Developer" use cases focused on exploiting design opportunities, avoiding cost by optimizing material and capital investment for engineering, procurement and construction activities, and achieving code compliance for buildings and other infrastructure development.

The use cases in the Operations \& Maintenance "Utilities" section are aimed at optimizing the operations of various energy assets across sectors (generation, storage, consumption) to reduce energy, greenhouse gas emissions, and operations and maintenance costs. These interventions rely on reducing energy use, optimizing distributed energy resources (DER) asset development and operation, reducing peak load, promoting demand side management and energy efficiency measures. Other O\&M activities that are of interest at the district level include optimization of district energy systems for heating, cooling, and thermal storage. Developers also aspire to undertake proactive fault detection and diagnostics, which allow asset owners, building managers, and utilities to carry out safety and maintenance procedures to optimize resource utilization and help drive down the asset's operational costs.

Table 1: CityEOS metrics and data types

\begin{tabular}{|c|c|c|c|c|c|c|}
\hline & 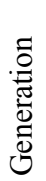 & 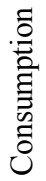 & 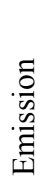 & 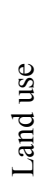 & 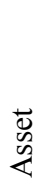 & î \\
\hline Units per fuel & $\mathrm{X}$ & $\mathrm{X}$ & & & & \\
\hline RE in fuel mix & $\mathrm{X}$ & & & & & \\
\hline GHG emissions & & & $\mathrm{X}$ & & & \\
\hline Air quality index & & & $\mathrm{X}$ & & & \\
\hline \# certified buildings & & & & & $\mathrm{X}$ & \\
\hline \# EV chargers & & & & & $\mathrm{X}$ & \\
\hline RE and storage installed & & & & & $\mathrm{X}$ & \\
\hline \$ generated & $\mathrm{X}$ & $\mathrm{X}$ & & & & $\mathrm{X}$ \\
\hline \$ cost per square foot & & & & & $\mathrm{X}$ & $\mathrm{X}$ \\
\hline Return on Investment & $\mathrm{X}$ & $\mathrm{X}$ & & & & $\mathrm{X}$ \\
\hline $\mathrm{kWh}$ or kBtu saved & & $\mathrm{X}$ & & & & \\
\hline \$ saved & $\mathrm{X}$ & $\mathrm{X}$ & & & & $\mathrm{X}$ \\
\hline Reduction in GHG & & & $\mathrm{X}$ & & & \\
\hline Dist from energy services & & & & $\mathrm{X}$ & $\mathrm{X}$ & \\
\hline Walkability scores & & & & $\mathrm{X}$ & $\mathrm{X}$ & \\
\hline Energy Use Intensity & & $\mathrm{X}$ & & & $\mathrm{X}$ & \\
\hline
\end{tabular}


Evaluation of the Need for and Design of a City Energy

Operations System

\begin{tabular}{|c|c|c|c|c|c|c|c|c|}
\hline & \multicolumn{4}{|c|}{ City/ Campus } & \multicolumn{2}{|c|}{ Developer } & \multicolumn{2}{|c|}{ Utility } \\
\hline Users & $\begin{array}{c}\text { Dept. of } \\
\text { Environment } \\
\text { and associated } \\
\text { Consultants }\end{array}$ & City Manager & $\begin{array}{l}\text { Planning and } \\
\text { Transport } \\
\text { Commission }\end{array}$ & $\begin{array}{l}\text { Public Works } \\
\text { Dept. } \\
\text { (city owned } \\
\text { assets) }\end{array}$ & $\begin{array}{l}\text { Architect/ } \\
\text { Planner/ } \\
\text { Engineer }\end{array}$ & \begin{tabular}{|c|} 
BOOM \\
Developers \\
(Build-Own- \\
Operate-Manages \\
Campus owner
\end{tabular} & Utility & $\begin{array}{l}\text { Private DER } \\
\text { Asset Owner }\end{array}$ \\
\hline $\begin{array}{l}\text { P1. Energy inventorying, } \\
\text { reporting and compliance }\end{array}$ & - & 0 & - & 0 & - & - & ○ & e \\
\hline 2. Sustainability planning & $\bullet$ & $\bullet$ & $\bullet$ & - & $\bullet$ & $\bullet$ & $\bullet$ & e \\
\hline 3. Target setting & $\bullet$ & $\bullet$ & $\bullet$ & - & - & $\bullet$ & O & O \\
\hline P4. Longitudinal benchmarking & 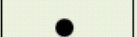 & O & - & - & - & ○ & ○ & 0 \\
\hline $\begin{array}{l}\text { P5. Cross-sectional } \\
\text { benchmarking }\end{array}$ & ○ & ○ & - & - & ○ & • & (1) & 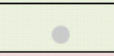 \\
\hline D1. Asset design opportunities & - & - & $\bullet$ & - & - & ○ & ○ & - \\
\hline D2. Asset code compliance & $\bullet$ & - & - & - & - & - & - & $\bullet$ \\
\hline 01. Improve energy efficiency & 0 & - & - & - & $\bullet$ & ○ & ○ & - \\
\hline $\begin{array}{l}\text { 22. Reduce cost and/or } \\
\text { generate revenue }\end{array}$ & - & - & - & 0 & 0 & 0 & ㄴ & 0 \\
\hline $\begin{array}{l}\text { D3. Maintenance (Planned and } \\
\text { potentially predictive) }\end{array}$ & - & - & - & 0 & - & 0 & $\bullet$ & ○ \\
\hline $\begin{array}{l}\text { D4. Optimize electric loads eg. } \\
\text { DR, peak load, DSM }\end{array}$ & - & - & - & 0 & - & 0 & 0 & 0 \\
\hline $\begin{array}{l}\text { 05. Optimize thermal loads e.g. } \\
\text { district energy systems }\end{array}$ & - & - & - & - & - & - & 0 & - \\
\hline $\begin{array}{l}\text { Priorities } \\
\text { High but for internal track }\end{array}$ & Hig & $\mathrm{Mec}$ & lium & $\begin{array}{rr}\text { Key u } \\
\text { BOON } \\
\text { blocks } \\
\text { N/NA Assets }\end{array}$ & $\begin{array}{l}\text { rs } \\
\text { developers, } \\
\text { ities that o } \\
\text { clude build }\end{array}$ & $\begin{array}{l}\text { Corporate and u } \\
\text { wn their electric } \\
\text { ing, equipments }\end{array}$ & $\begin{array}{l}\text { ersityc } \\
\text { ity } \\
\text { ERs and }\end{array}$ & uses, Eco \\
\hline
\end{tabular}

Figure 2: CityEOS Use cases and stakeholder priorities

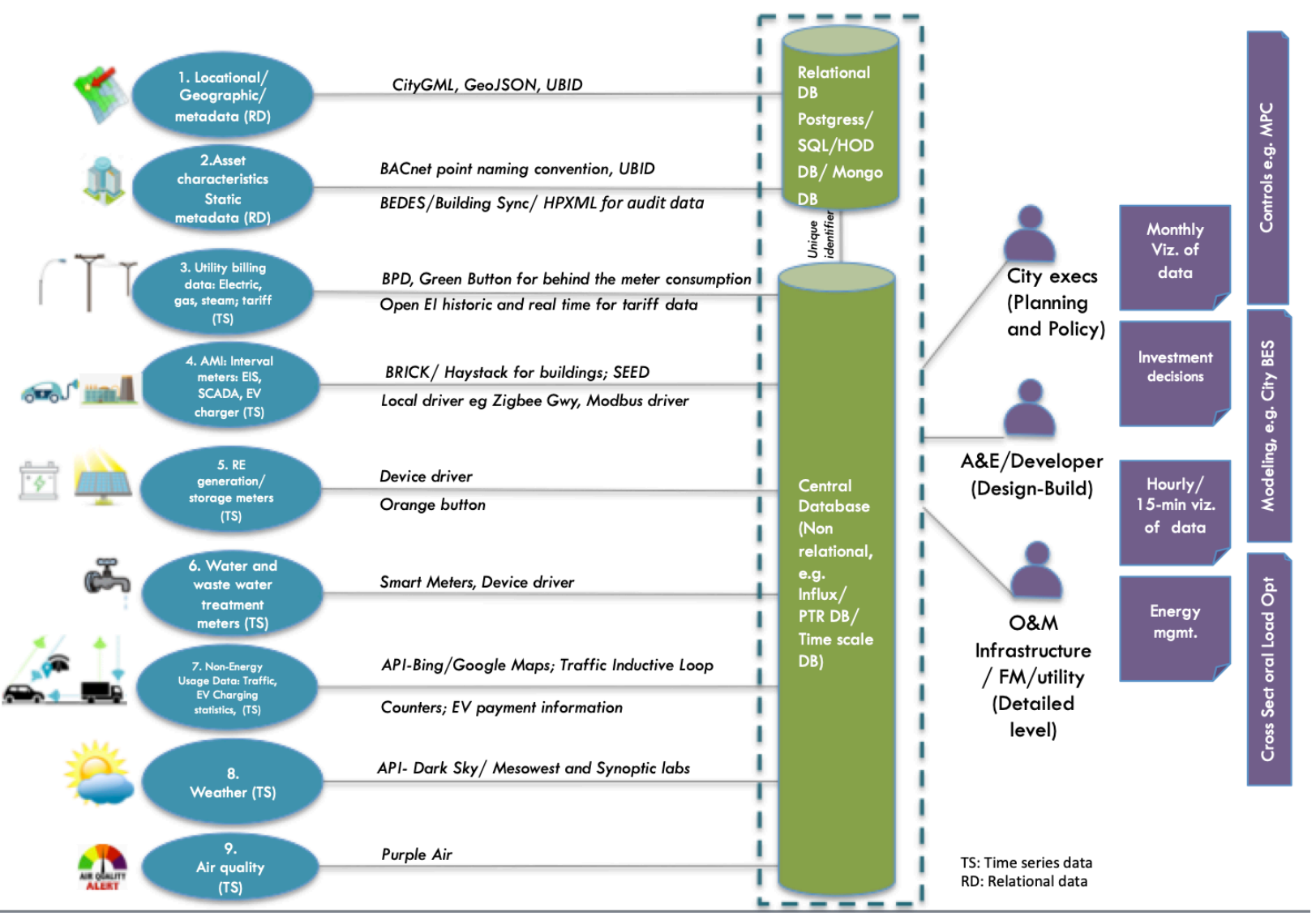

Figure 3: Simplified Architecture diagram of CityEOS 
For each use case we mapped the desired metrics, and the associated data sources by data types (a subset of these can be seen in Table 1), of which some of the more significant categories are: generation, consumption, emissions, land-use, asset, cost, weather, outage and maintenance. This categorization is consistent with the concepts of a CityEOS and the description of each of the key uses cases for different stakeholders as described by the three groups shown in Figure 2.

\subsection{CityEOS Architecture}

Using our findings from the process described in Figure 1, we created a CityEOS simplified concept shown in Figure 3. This architecture diagram shows the components that are suggested for a CityEOS platform. The CityEOS starts with data acquisition from both static metadata and time-series data. There must be provision for developing interfaces to collect both types of data: they could be a web APIs or device drivers to collect data from sensors, or static data such as CSV files etc.

The next component of the platform is data storage. Data should be stored in a database to allow one to query it for various data visualization and analysis tasks. An ideal way to store data would be to use a conventional database (e.g: PostgreSQL, SQLite, MongoDB etc.) to store the static metadata, along with some unique identifier linking to the time-series data. For the continuous timeseries data, identified by the unique identifier stored in the metadata database, we suggest storing it in a time-series database, which have been built to store data with timestamps and have optimized their performance for time based data insertion and data retrieval (e.g: InfluxDB [3], TimescaleDB [4]).

Once the data acquisition and storage has been engineered, the next components are the applications and visualizations built on top of the stored data. Based on the data availability, these are developed to meet the stakeholders' use cases. The CityEOS framework should support visualizations that can help a city to start using its data effectively. These could be specific to the type of stakeholder who is accessing the platform as well. Some of the promising applications include model predictive control for optimization of district energy systems, and a city-wide building energy efficiency savings application that can integrate rooftop solar, storage and load optimization between buildings and EV charging.

\section{CONCLUSIONS}

We have described a CityEOS reference framework for the data acquisition, analysis, and abstraction of city energy data to inform key city-scale energy analysis and use cases. While these use cases are captured in the reference specification, we also assessed aspirational use cases, such as energy equity [2] and energy resilience. While cities are interested in energy efficiency, equity and resilience, further research is needed to define the data collection and analysis needs to support this and other use cases.
The key potential users of a CityEOS may be organizations that own and manage their assets, such as cities that own municipal electric utilities, corporate and college campuses, and district developments using innovative models such as BOOM (BuildOwn-Operate-Manage) developers, and Ecoblock development models.

As cities become denser and seek to balance urban systems and sustainability, digitalization is an important part of energy systems analysis. City energy managers are interested in energy forecasting as well as operations and analysis tools. Cities are evaluating emerging trends such as electrification of transport and building thermal equipment, and more DERs coming online with solar PV, electric and thermal storage and demand side management. Hence, understanding the energy flows across multiple sectors is becoming critical. Data sharing and exchange between data owners and users, data visibility across multiple sectors, data aggregation up the value chain, and interoperability are of growing interest. For example, cities are tracking building stock characteristics and energy data and linking these data with building energy code compliance. Tracking and reporting key metrics across diverse use cases is a crucial factor to extract more value from existing information.

The full report on this research will describe each of the use cases and data elements in more detail. Future work is needed to evaluate the challenges in adopting use of standard data schemas, such as the use of CityGML [5], BEDES [6], SEED [7] and other standards. One huge challenge is that much of the data may not be available in electronic, or cybersecure form. Many cities lack the resources to implement platforms like those described in CityEOS. Thus, it is critical to prioritize the design and build-out of these platforms to ensure they provide near-term value, and are extensible and agile.

\section{ACKNOWLEDGMENTS}

The authors would like to thank Harry Bergmann and Andrew Burr from U.S. Department of Energy's Building Technologies Office. This work was supported by the Assistant Secretary for Energy Efficiency and Renewable Energy, Building Technologies Office, of the U.S. Department of Energy under Contract No. DE-AC02$05 \mathrm{CH} 11231$

\section{REFERENCES}

[1] Alexandra Aznar, 2015. City-Level Energy Decision Making: Data Use in Energy Planning, Implementation, and Evaluation in U.S. Cities. National Renewable Energy Laboratory.

[2] Max Wei, et al., 2017. Building a Healthier and More Robust Future: 2050 LowCarbon Energy Scenarios for California. California Energy Commission. Publication Number: CEC-500-2019-033.

[3] Influxdata. InfluxDB v1.7 documentation. https://docs.influxdata.com/influxdb/v1.7/. Accessed September 2019

[4] Timescale. TimescaleDB documentation. https://docs.timescale.com/latest/main. Accessed September 2019

[5] Open Geospatial Consortium. CityGML website: https://www.opengeospatial.org/standards/citygml. Accessed September 2019.

[6] Building Energy Data Exchange Specification (BEDES). BEDES website: https://bedes.lbl.gov/bedes-online. Accessed September 2019.

[7] Standard Energy Efficiency Data platform (SEED). SEED website: http://seedinfo.lbl.gov/. Accessed September 2019. 